\title{
LIII. The measurement of small gaseous pressures
}

\section{Charles F. Brush}

To cite this article: Charles F. Brush (1897) LIII. The measurement of small gaseous pressures , Philosophical Magazine Series 5, 44:270, 415-421, DOI: 10.1080/14786449708621084

To link to this article: http://dx.doi.org/10.1080/14786449708621084

$$
\text { 曲 Published online: } 08 \text { May } 2009 .
$$

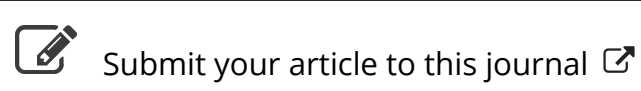

\footnotetext{
Џ Article views: 2
}

Q View related articles $₫$ 


\section{The Measutement of Small Gastous Pressures. By Charles F. Brush*}

DRIOR to the invention of the McLeod vacuum gauge, the measurement of even moderately small gaseous pressures was difficult, and subject to large errors. The introduction of the McLeod gauge, however, early in the seventies, seemed to solve the problem. In its ordinary form, and for most purposes, this beautiful insirument admirably serves the purpose for which it is designed. But when very accurate measurements of pressures as small as a few millionths only, of atmospheric pressure are desired, its performance is extremely unsatisfactory and vexatious. As is well known, the chief cause of the difficulty is the unequal and variable capillary depression of the two small columns of mercury, whose difference in height indirectly serves as the measure of pressure. Accurate measurement of this capricious difference obviously avails nothing.

Three or four years ago, I was engaged in an investigation requiring frequent and simultaneous measurements of slight, but different pressures, in two large glass globes connected by a capillary tube. For this purpose I constructed and carefully callibrated two large McLeod gauges. The internal diameter of the mercury tubes was about 3 millimetres, and they were made from contiguous parts of the same glass tube selected for uniformity of bore. These gauges were often compared by measuring the same vacuum with both; but they rarely gave concordant results. Indeed it was not uncommon at high exbaustions, for one or the other of them to indicate a negative vacuum; that is to say, less than no pressure at all. The case of these two gauges is cited because of the opportunity they afforded for comparison. In prior work I had, like most experimentalists, used but one gauge; and while always suspicious of its indications, had no means of knowing how large its errors might be.

The phenomenon which I next desired to investigate, was the spontaneous evolution of gas from glass, and other surfaces in high vacua. For this purpose an accurate and entirely reliable means for measuring very small pressures was necessary, because I could not afford to wait months or years for the evolution of sufficient gas to be detected with certainty by the old gauges. To meet these requirements I designed, constructed, and learned how to use the modified form of

* Communicated by the Author, having been read before the American Association for the Advancement of Science, August 12, 1897. 
McLeod gange which it is the purpose of this paper to discuss. It was deemed necessary to provide an apparatus capable of easy use, and giving results having a probable error not greater than a fiftieth part of a millionth of atmospheric pressure. My hopes of aitaining this high ideal were far more than realized, as the sequel will show. Instead of having to wait days or weeks, in the course of my investigations, for the evolution of a measurable quantity of gas as had been expected, the progress of evolution could be noted from hour to hour; and the increase in the rate of evolution due to a rise of one degree in the temperature of the laboratory was unmistakable.

The diagram herewith shows the essential parts of my apparatus. The bulb $A$, of the gauge, is made conical in its upper part to avoid adhesion of gas bubbles when the mercury rises. This bulb holds about eleven pounds of mercury. $\mathrm{B}$ and $\mathrm{C}$ are the gauge-head and comparison tube respectively. They are nearly 20 millimetres inside diameter, and are made from contiguous parts of the same carefully selected tube. $D$ is the usual air-trap, and $E$ is a long glass tube, with flexible pure rubber connexions to the lower end of the gauge stem and the mercury cistern $F$. The latter is monnted on a carriage $G$, which moves vertically on fixed guides. The height of the carriage is adjustable, at the upper end of its range of motion, by means of the screw $H$, thumb-nut $I$, and forked support $K$. The screw is pivoted to the carriage, so that it may swing out of the fork when the carriage is lowered. $\mathrm{L}$ is a pinch-cock with screw, for regulating the flow of mercury, or stopping it altogether, while pumping out the trap $\mathrm{D} . \mathrm{N}$ is a bulb containing phosphorus pentoxide, to keep the interior of the gauge and other parts of the apparatus perfectly dry. $P$ is a very elaborate cathetometer for observing the mercury columns in $\mathrm{B}$ and $\mathrm{C}$. This beautiful instrument has a revolving colnmn with vertical scale, and vernier with microscope, reading to hundredths of a millimetre. The eyepiece micrometer reads directly to hundred ths of a millimetre, and the divisions on the revolving head of the screw are so open, that tenths of divisions are easily and certainly estimated by an experienced eye; thus permitting the micrometer to be read directly to thousandths of a millimetre. Of course the cathetometer is perfectly located, not as shown, but with the objective of its telescope equally distant from the axes of the tubes $\mathrm{B}$ and $\mathrm{C}$ when it is alternately. directed to them; and at such a distance that its micrometer readings correspond to a millimetre scale. The whole apparatus is located in a basement room, on a stone floor, whereby vibrations are reduced to a minimum. 
of Small Gaseous Pressures.

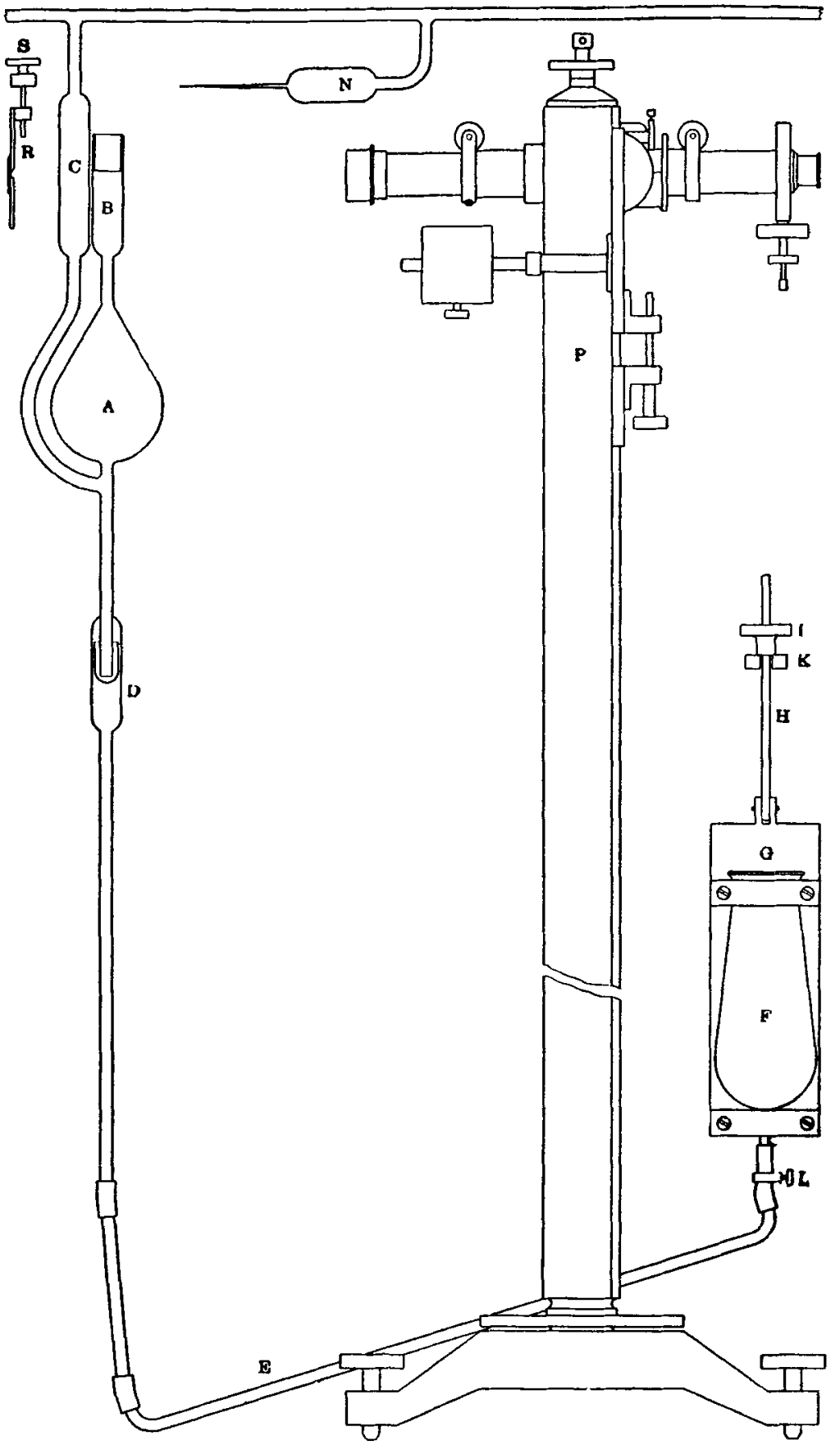

Plil. Mag. S. 5. Vol. 44. No. 270. Nov. 1897. $2 \mathrm{H}$ 
The most important part of the gauge is the head $B$. The purpose of its great diameter is the reduction of capillary depression in its mercury column. But its size necessitates a very close approach of the mercury to its upper end, in order to sufficiently reduce its capacity. Yet the remaining space must be measurable by the cathetometer with the utmost precision. Hence the glass must not be distorted by heating, and the closed end just over the mercury must be sharply defined. In constructing this part of the apparatus, I selected a piece of beavy tubing which would just slip inside of $B$, with the least possible clearance. One end of this tube was closed as squarely as possible by fusion, and then ground with fine emery and a suitable tool to a convex spherical surface of long radius. Care was taken to make the centre of curvature lie in the axis of the tube, and the ground surface was left unpolished to facilitate observation. A suitable length of the closed end of the tuhe was then cut off, slipped into B, and both tubes were fused together at their open ends, as shown.

For callibrating the head B, a ground-glass stopper with a capillary duct was fitted to its neck, before the latter was sealed to the bulb A. The head was then filled with mercury by boiling, thus completely filling the small space between its wall and the cap. After cooling, the stopper was inserted to expel all excess of meroury, and the whole weighed. Next the head was emptied, and the mercury in the annular space distilled ont. Again the head was very nearly filled with mercury, without allowing any to get into the annular space, and weighed as before; and the space between the top of the mercury and the convex end of the head was very carefally measured by the cathetometer. This process of weighing and measuring was repeated several times, with less mercury each time. Thus the capacity of a vertical millimetre of the head was ascertained, as well as the capacity that would remain, if the top of the meniscus of mercury just touched the convex end of the gauge above it. Finally the neck was sealed to the bulb A, and the capacity of head, neck, and bulb combined was found by weighing them empty, and again filled with mercury.

For lighting the top of each mercury column, a narrow horizontal slit in an opaque screen $\mathrm{R}$ is used. The slit is covered with a strip of ground glass, and obliquely illuminated by an electric lamp. The screen and slit are vertically adjusted by a thumb-screw $\mathrm{S}$. The heat of the lamp is prevented from reaching the mercury columns, and head B, by a thick screen. This is very necessary.

In order to get the best results from the apparatus, many 
precautions are necessiry. After filling $A$ and $B$ with mercury, time must be allowed for the compressed gas to cool. The effect of changing barometric pressure is nearly eliminated by so regulating the quantity of mercury in $F$ that its surface is in the small tube at the bottom of the cistern, when the gauge is properly filled. Its area is then very small, as compared with that in $\mathrm{B}$ and $\mathrm{C}$. The height of the meniscus in both tubes is easily adjusted sensibly equal by a little manipulation. I always raise the mercury above the point at which readings are to be taken, and then lower it, so as to read on a falling meniscus. This is bighly important.

Some trouble was occasionally experienced at first from electrostatic induction between the mercury in B and the glass above it. This was shown by distortion of the meniscus when it was brought very near the glass. The difficulty wis partially, but not wholly remedied by putting mercury in the outside open end of the gauge-bead, and connecting it by a flexible conductor with the mercury in the cistern F. A complete remedy was effected by moistening the inside of the gauge-head with a dilute solution of phosphorus pentoxide. This became completely dried by the anhydrous phosphorus pentoxide in N, but was of course not delyddrated; and hence always remains conducting, and dissipates the static charge.

Large pressures, up to a thousand millionths or more, are readily measured with this apparatus by finding with the cathetometer the distance between the mercury in $B$ and the end of the head above it; from this is quickly calculated the necessary multiplier for the number of millimetres difference in height between the columns in B and C, also measured by the cathetometer, in order to express the result in millionths. For very small pressures, the micrometer wires are set at such a distance apart as to give a convenient constant (usually 2); and the column in B is adjusted this distance away from the glass; careful allowance being made for the thickness of the wires. Then the micrometer is used for repeated measurements of the difference in height of the mercary in B and C. The disturbing effect of bias is entirely eliminated by giving the micrometer screw a partial turn after each reading. Thus the next measurement is made without any knowledge of its difference from the preceding one, until the eye is removed from the telescope.

In my early experience with the apparatus, unusually careful measurements of very small pressures were often made to determine how far its indications might be relied upon. In this connexion I quote as follows from my notes, under date of Feb. 20,1895, concerning the last one of a series of pressure $2 \mathrm{H} 2$ 
determinations :- " Following is the last reading in detail, showing the extreme accuracy of these measurements:

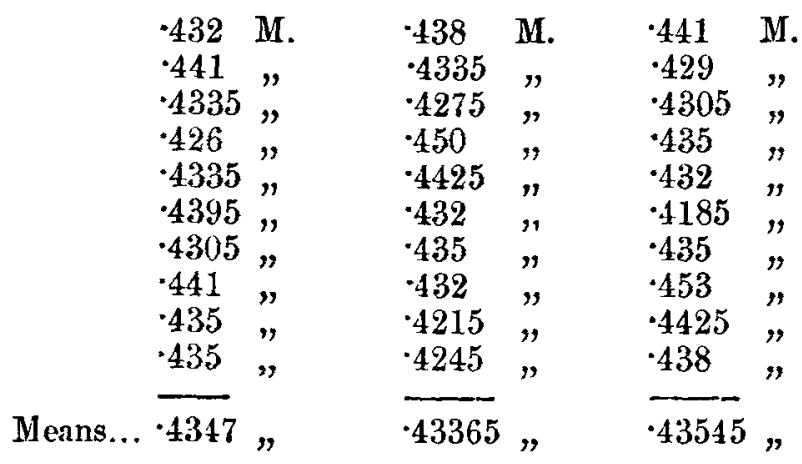

"Mean of all the readings, $-4346 \mathrm{M}$.

" Readjusted zero-point of micrometer before each reading of each set. Partially emptied gange and readjusted capillary depression before each set of readings. The first series bas no known source of error. The second and third series were made during wind-squall, and surface of mercury was often tremulous. In the third series, capillary depression was perceptibly, though very slightly, nnequal, in direction to make readings too high."

In the above quotation, "M" means millionths of atmospheric pressure. The calculated probable error of the thirty readings taken together is only ninesty-two hundredths of a unit in the third decimal place; that is to say, less than a thousandth part of a millionth of atmospheric pressure! The probable error of the three mean results, considered as single readings, is only eleven hundredths of a nnit in the third decimal place of millionths. The net result may be expressed as follows, in terms of atmospheric pressure:-Considered as thirty measurements :

$$
0 \cdot 00000043460 \pm 0.00000000092 .
$$

Considered as three measurements :

$$
0.00000043460 \pm 0.00000000011 .
$$

Here we have the measurement of a total quantity of less than balf a millionth of atmospheric pressure, with a probable 
error of only about a fifth of one per cent. of the quantity measured.

To show how small is the effect of variable capillary depression in the large mercury column, the following measurenents were made July 25, 1897. No correction was made of accidental capillary differences, but the columns were always observed with a falling meniscus. The zero of the micrometer was freshly adjusted for each reading; and before each of the six sets of readings the mercury was lowered, and then readjusted to the proper height in the gauge-head.

$\begin{array}{ccccccc} & \text { M. } & \text { M. } & \text { M. } & \text { M. } & \text { M. } & \text { M. } \\ 2 \cdot 210 & 2 \cdot 203 & 2 \cdot 209 & 2 \cdot 198 & 2 \cdot 198 & 2 \cdot 202 \\ \cdot 204 & \cdot 195 & \cdot 202 & \cdot 203 & \cdot 204 & \cdot 198 \\ \cdot 209 & \cdot 198 & \cdot 204 & \cdot 208 & \cdot 200 & \cdot 196 \\ \cdot 203 & \cdot 204 & \cdot 210 & \cdot 200 & \cdot 196 & \cdot 208 \\ \text { Means } & \frac{\cdot 203}{2 \cdot 2058} & \frac{\cdot 192}{2 \cdot 1984} & \frac{\cdot 202}{2 \cdot 2054} & \frac{\cdot 198}{2 \cdot 2014} & \frac{\cdot 196}{2 \cdot 1988} & \frac{\cdot 203}{2 \cdot 2014}\end{array}$

Calculating the probable errors, we have:

Six mean readings..... $2 \cdot 20187 \mathrm{M} . \pm 0 \cdot 00073 \mathrm{M}$.

All readings .......... 2.20187 " \pm 0.00059,

The effect of not equalizing the capillary depression is very apparent when these results are compared with the earlier ones quoted. But on account of increased skillfulness of observation, due to long experience, the individual readings of each set are more uniform than before; so that the net result is better.

In this example we have the measurement of about two millionths of atmospheric pressure, with a probable error of only one part in three thousand of the quantity measured.

From the foregoing we may safely conclude that with the apparatus described, small gaseous pressures may be easily measured with a probable error of less than a thousandth part of a millionth of atmospheric pressure.

The smallness of this fraction is difficult to realize. It is comparable with a thousandth part of a milligram, in a thousand grams; or a single kernel of wheat in two thousand bushels; or an inch and a half in the circumference of the earth; or the thickness of a sheet of tissue paper in 16 miles. 